Classification

Physics Abstracts

$06.50-42.30-81.05$

\title{
Morphological Determinations of Fiber Composites
}

\author{
Luc Avérous $\left({ }^{1}\right)$, Jean-Christophe Quantin $\left({ }^{1}\right)$, Dominique Lafon $\left({ }^{2}\right)$ and Alain Crespy $\left({ }^{1}\right)$ \\ $\left({ }^{1}\right)$ École des Mines d'Alès, Laboratoire Matrices, Matériaux Minéraux et Organiques, \\ 6 avenue de Clavières, 30319 Alès, France \\ $\left({ }^{2}\right)$ École des Mines d'Alès, Laboratoire Poudres, Microstructures, Macrostructures, Mines, \\ Gisements, 6 avenue de Clavières, 30319 Alès, France
}

\begin{abstract}
Résumé. - De manière à développer des modèles mécaniques, il est nécessaire de déterminer certains paramètres intrinsèques au matériau étudié. Dans cette étude, nous proposons différentes techniques pour approcher des paramètres de dispersion de fibres dans des composites. Les résultats obtenus sur des polypropylènes chargés en fibres de verre courtes différenciés par la longueur des fibres, présentent l'évolution des paramètres sélectionnés avec l'état d'orientation et la granulométrie des fibres.
\end{abstract}

\begin{abstract}
To develop mechanical models of a material, it is necessary to determine some of its intrinsic parameters. In the present study, we propose different techniques for determining some dispersion parameters of fibers in composites, in a plane space. The results show on various short fiber glass reinforced polypropylenes that are differentiated by their fiber lengths, the evolution of the selected dispersion in relation with the orientation and the granulometry of the fibers.
\end{abstract}

\section{Introduction}

Fiber composites are being increasingly used in a large number of applications. Fibers give to the matrix better mechanical properties, such as stiffness, impact resistance, etc.

With a determined fiber morphology and composition, the fiber composite morphology is defined by the orientation and the dispersion of the fibers inside the matrix. There is growing evidence in the literature that these parameters are critical factors in the mechanical performance of composite materials [1,2].

Nowadays, image analysis techniques are increasingly being used to determine microstructure or morphology [1]. For instance, some authors have developed techniques by coupling image processing and microscopy to determine fiber length [3-8], or fiber orientation [9-13]. Waterbury and Drzal [14] determined volume fractions by image analysis and correlated these results with others obtained from the more standard method based on acid digestion. Image analysis has been used by some authors to determine dispersion [15]. But, most of the different approaches are to be found outside the standard literature on composites. 
Table I. - Size results, average lengths for the four used materials.

\begin{tabular}{|c|c|c|}
\cline { 2 - 3 } \multicolumn{1}{c|}{} & $\begin{array}{c}\text { number weighed } \\
\text { mean length }(\mu \mathrm{m})\end{array}$ & $\begin{array}{c}\text { mass weighed } \\
\text { mean length }(\mu \mathrm{m})\end{array}$ \\
\hline $\mathrm{CFg}$ & 470 & 700 \\
\hline SFg1 & 110 & 210 \\
\hline SFg2 & 60 & 100 \\
\hline Pg & 14 & 14 \\
\hline
\end{tabular}

To define the dispersion, we find in image analysis literature [16-18] different methods which can be adapted and applied to estimate the dispersion of multiphased systems in a plane space. In order to illustrate these estimations two methods based on mathematical morphology are presented: the covariogram method allows structures to be analysed; the contact distribution function were determined in order to test and estimate interparticular voids.

The principal aim of this study is to present different techniques based on image analysis that could be used to determine the morphology of fiber composites. Methods to determine orientation have been described in recent papers $[12,13]$. So, here we focus more particularly on dispersion, which has not until now been much described in the literature. Methods and corresponding results are presented. The fiber composite selected for this study is short fiber glass reinforced polypropylene.

\section{Preliminary Operations}

2.1 Preparation of Materials. - Fibers and polypropylene were mixed in a co-rotating twin-screw extruder. The material was produced in the form of end gate injection bar with a cross section of $10 \mathrm{~mm} \times 4 \mathrm{~mm}$. All the different fibers used had the same diameter (14 microns). The fiber content was close to $30 \mathrm{wt} \%$. Different composites (Cfg, Sfg1, Sfg2 and Pg) were produced by varying only the average fiber length. Table I lists the products with the corresponding average size of the fibers. We can see that the product Pg is quite different: the filler is close to a powder (length $\approx$ diameter).

The granulometric data were obtained by the processing of an automatic image analysis technique which were developed in the laboratory [8]. Fibers were spread between two glass slides and examined under a polarizing optical microscope.

For composite examination, a central cross section of the bar was cut (perpendicularly to the injection sense) and carefully polished.

2.2 Microscopy and Image Processing. - Observations were made by scanning electronic microscopy (JEOL JSM-35CF) in backscattered electron mode. $20 \mathrm{kV}$ high tension was applied. The magnification was set at $\times 300$. To obtain a better image quality avoiding electric discharges on the sample surface and reducing noise, the specimen was first coated with a thin layer of carbon [19] and a conductive silver bridge was established with its support.

The microscope set up with an acquisition system (KEVEX-Delta) provides grey level images (256 levels). 

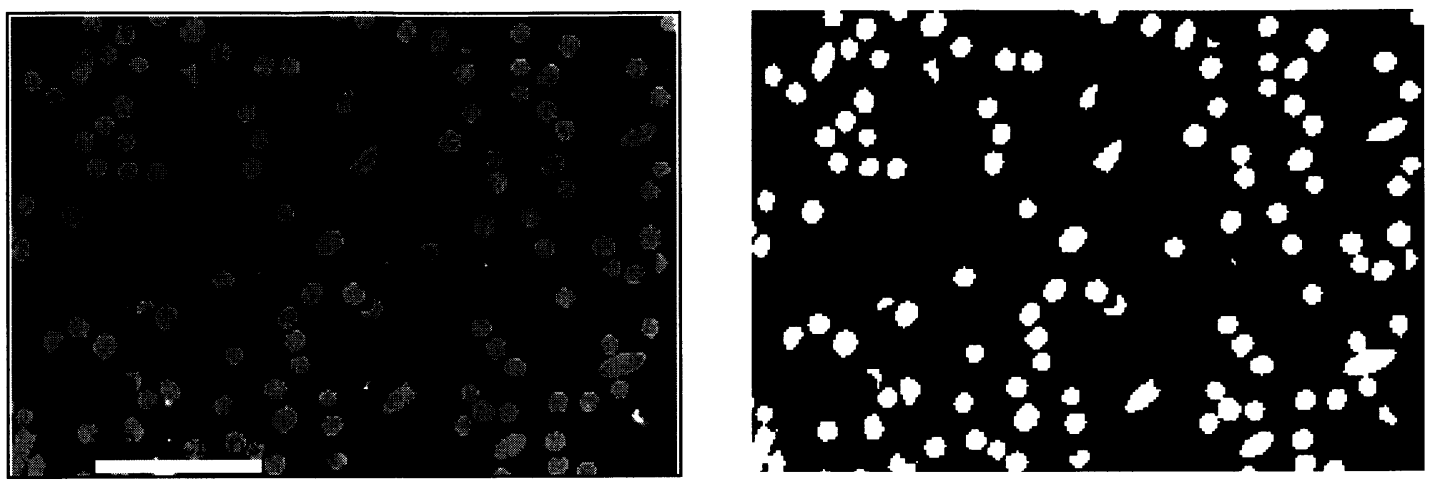

100 microns

Fig. 1. - Illustration of a grey level image of a polished section, with the corresponding binary image.

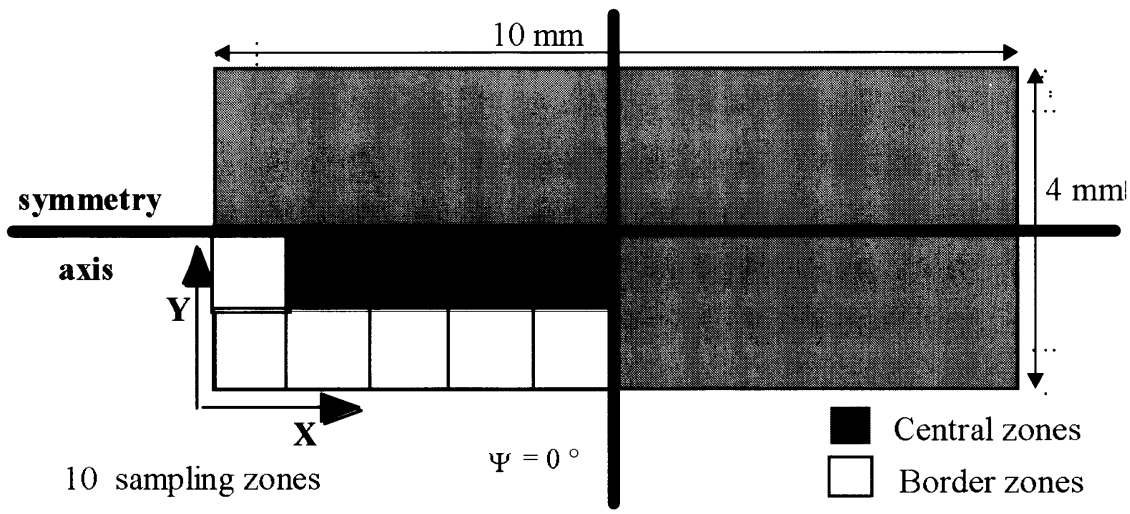

Fig. 2. - Illustration of the sampling strategy.

Image treatments are done on a dedicated image analysis system: PC-Visilog 3.6. Electronic deformations (SEM, videocard, ...) were corrected by interpolation transformations. An image size of $512 \times 340$ pixels was obtained (Fig. 1). Top hat transformations [16, 17] were carried out to clean the image. After thresholding operations, erosion/reconstruction transformations are used in order to eliminate artefacts on binary images.

\section{Methods of Determining Dispersion Parameters}

3.1 SAmpling Mode. - The sampling mode for injected composites takes usually into account core and skin behaviour [20]. Fibers orientation states are different between central and border zones. But it is not always easy to differentiate clearly between the two types of zones by microscopic observation. Stereological approach was used; the section under study was divided into zones of equal area. It was verified that the cross section was symmetrical about the two main axes and the investigations were then limited to a quarter of the total surface [2]. Ten different samples were taken giving four central and six border zones (see Fig. 2). For the chosen microscopic magnification, each $1 \times 1 \mathrm{~mm}^{2}$ sampling zone was described by one image of about $290 \mu \mathrm{m} \times 410 \mu \mathrm{m}$. 


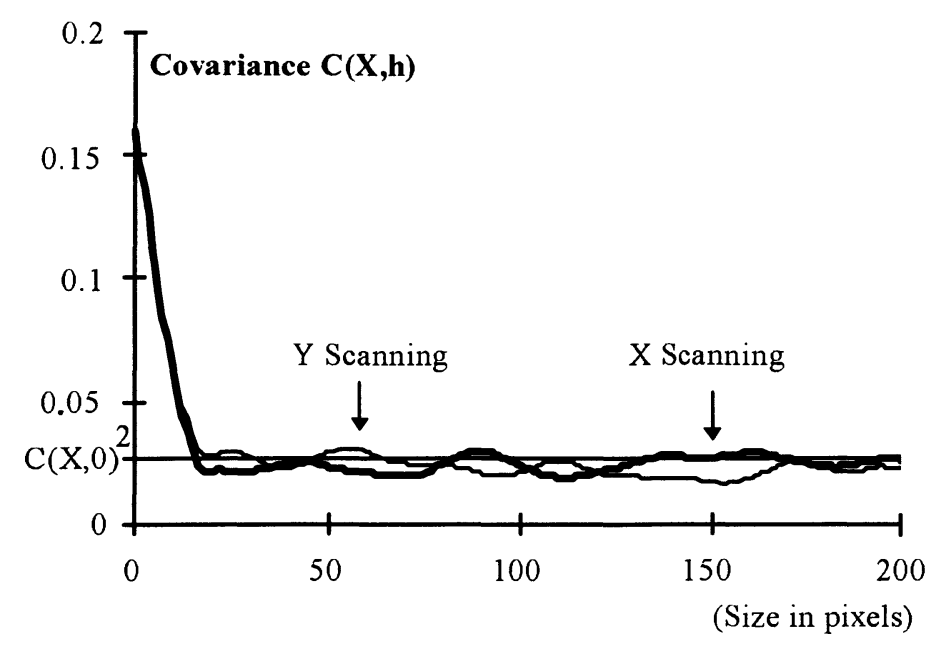

Fig. 3. - Covariogram corresponding to the image in Figure 1.

3.2 Covariogram Approach. - This technique is used to describe the state of dispersion of materials [16]. It can also be used to compare dispersion models with the observed dispersion and adjust them. It is based on structuring elements made of two points at distance $h$ apart to analyse correlations between each point $x$ on the image and the point at $x+h$.

Denoting $\mathrm{X}$ the analysed set, $\mathrm{Z}$ the frame of measurement, $A[\mathrm{Y}]$ the area of a set $\mathrm{Y}$, and $\mathrm{E}^{\mathrm{h}}[\mathrm{Y}]$ the eroded of set $\mathrm{Y}$, the covariance function $C(\mathrm{X}, h)$ is obtained without edge errors from [16]:

$$
C(\mathrm{X}, h)=\frac{A\left[\mathrm{E}^{\mathrm{h}}(\mathrm{X}) \cap \mathrm{E}^{\mathrm{h}}(\mathrm{Z})\right]}{A\left[\mathrm{E}^{\mathrm{h}}(\mathrm{Z})\right]}
$$

In practical terms for a plane space, the covariance is determined by the ratio of the area of the image eroded by $h$ adjusted by the total area of the measure mask $\mathrm{Z}$ eroded by $h$.

The covariogram is the plot of $C(\mathrm{X}, h)$ versus $h$ [16]. It has some interesting properties [16-18]. The negative initial slope is equal to the average intercept number per length unit, $N_{1}(\mathrm{X})$. An average free interparticular distance $d_{\mathrm{f}}$, can be defined as the mean chord length (or mean free path) in the matrix [21]:

$$
d_{\mathrm{f}}=\frac{1-V_{\mathrm{v}}(\mathrm{X})}{N_{\mathrm{l}}(\mathrm{X})}
$$

where $V_{\mathrm{v}}(\mathrm{X})$ is the filler volume fraction.

Considering the fiber section as a disk of diameter $d=14 \mu \mathrm{m}$, theoretical values of $d_{\mathrm{f}}$ can be obtained with the stereological equation:

$$
d_{\mathrm{f}}^{\prime}=\frac{1-V_{\mathrm{v}}(\mathrm{X})}{V_{\mathrm{v}}(\mathrm{X})} \times \frac{\pi}{4} d .
$$

A characteristic length scale of the structure, called the integral range, can be obtained by integration of $C(h, \mathrm{X})$ [16]. For each binary image analysed, the covariogram is measured for both $X$ and $Y$ axes (see Fig. 3). 


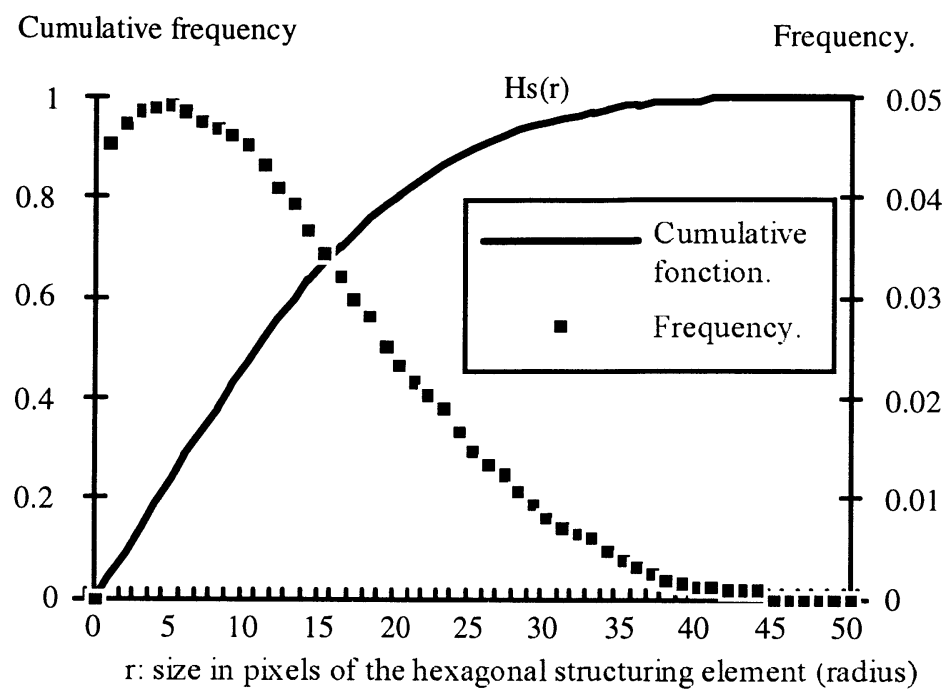

Fig. 4. - Contact distribution corresponding to the image in Figure 1. $H s(r)$ : contact distribution function.

3.2.1 Contact Distribution (Interparticular Distances). - Stoyan et al. [18] have defined a contact distribution function (CDF) for measuring distances between particles. Other authors did this by using the first contact law [17], the distance distribution function [22] or the length distribution function [23]. The CDF used is based on erosions by convex structuring elements of size $r$ (denoted $\mathrm{E}^{\mathrm{rB}}$ ). Using the measure mask theorem to get unbiased results, the contact distribution function $H_{\mathrm{s}}(r)$ is measured by [24]:

$$
H_{\mathrm{s}}(r)=1-\frac{A\left[\mathrm{E}^{\mathrm{rB}}\left(\mathrm{X}^{\mathrm{c}}\right) \cap \mathrm{E}^{\mathrm{rB}}(\mathrm{Z})\right]}{A\left[\left(\mathrm{X}^{\mathrm{c}}\right) \cap \mathrm{E}^{\mathrm{rB}}(\mathrm{Z})\right]},
$$

$H_{\mathrm{s}}(r)$ is equivalent to $P(l)[16]$ for linear structuring element.

Changing the framework, the distribution of distances between particles (Fig. 4) with hexagonal structuring element (close to an isotropic element) was established for each binary image. A dispersion parameter, the average contact distance $\left(d_{c}\right)$ is calculated from the cumulative distribution, $H_{\mathrm{s}}(r)$. It can be interpreted as an average interparticular distance between particles from border to border in all the space studied.

\section{Results and Discussion}

From covariograms for the different samples, the ratios of the integral range by the corresponding image size were presented in Table II. No covariogram dritt was observed. In all cases the structure analysed is smaller than the window size. From Sfg2 to Pg, the trend is a decrease of the integral range according the fiber length. Pg values are the lowest.

In Table II, one can notice that $d_{\mathrm{f}}$ and $d_{\mathrm{c}}$ results decrease with fiber length reduction (from Sfg2 to $\mathrm{Pg})$. The filler volumic fraction $V_{\mathrm{v}}(\mathrm{X})$ was determined from the filler mass fraction, which is obtained by pyrolysis of the matrix and weighing of the fibers.

The ratio $d_{\mathrm{f}} / d_{\mathrm{f}}^{\prime}$ is not equal to the unity. The determination of $d_{\mathrm{f}}^{\prime}$ is based on a discoidal fiber section but, on the one hand, the orientation of the fibers is not parallel to the injection sense, 
Table II. - Main dispersion results.

\begin{tabular}{|c|c|c|c|c|}
\cline { 2 - 5 } \multicolumn{1}{c|}{} & CFg & SFg1 & SFg2 & Pg \\
\hline Ratio integral range/frame size, & 0.16 & 0.21 & 0.18 & 0.15 \\
according to $X$ and $Y$ axes & 0.33 & 0.34 & 0.32 & 0.25 \\
\hline Volume fraction, $V_{\mathrm{v}}(\mathrm{X})$ & 0.126 & 0.131 & 0.133 & 0.133 \\
\hline Free interparticular distance, $d_{\mathrm{f}}(\mu \mathrm{m})$ & 80 & 76 & 74 & 64 \\
Ratio $d_{\mathrm{f}} / d_{\mathrm{f}}^{\prime}$ & 1.05 & 1.04 & 1.06 & 1.12 \\
\hline Average contact distance, $d_{\mathrm{c}}(\mu \mathrm{m})$ & 24.4 & 23.4 & 23.0 & 19.4 \\
\hline
\end{tabular}

then the fiber mark is quite elliptical (Fig. 1). On the other hand, we have various fiber ends on the section (proportional to the fiber length - see Pg results). So, the determination of $d_{\mathrm{f}}^{\prime}$ cannot be totally carried out.

The difference between border and centre zones is not totally clear for the different product but the trend is that interparticular distances are greater in border zones [2]. Orientation results [13] for different products can show that fibers become more parallel to the direction of injection as fiber length increases. The behaviour of the fibers during the mould filling flow leads to different filler orientations between border and centre zones (skin and core behaviour). In border zones the fibers are more parallel to the flow direction. These orientations influence the dispersion parameters; the more the fibers are perpendicular to the cross section studied, the greater the distances in the plane between each one (from border to border) increase.

Nevertheless, it appears that fiber lengths are not different enough to cause considerable differences between the dispersion data obtained for the composites studied, particularly between Sfg1 and Sfg2. Working in the plane is a limitation to the study of dispersion which should ideally be studied in three dimensions. An adequately developed model should be able to achieve this transition. But until now, to the authors' knowledge, only some preliminary investigations have been carried out for fiber composites by Pelikan et al. [25] without conclusive results.

\section{Conclusion}

In this paper, some different techniques for the analysis of various fiber glass reinforced polypropylenes have been presented. They are based on image analysis coupled with microscopy. Results indicate that interesting parameters can be obtained from covariogram and contact distribution methods. Their variations correlate with fiber length evolution which itself is linked with orientation.

The development of a three-dimensional model based on rod particles could be an interesting way to characterize the volumic dispersion of the fillers. Appropriate mechanical models including the dispersion parameters that we have determined have to be now investigated. 


\section{References}

[1] Guild F.J. and Summerscales J., Microstructural image analysis applied to fibre composite materials: a review, Composites 24 (1993) 383-393.

[2] Avérous L., Étude par analyse d'images de la microtexture d'un polypropylène chargé fibres de verre broyées - Relation avec les propriétés du matériau, Thèse de Doctorat de l'École des Mines de Paris (1995).

[3] Lunt J.M. and Shortall J.B., The effect of extrusion compounding on fibre degradation and strength properties in short glass-fibre-reinforced nylon 6.6, Plas. Rubber: Process. Sept. (1979) 108-114.

[4] Sawyer L.C., Determination of Fiberglass lengths: Sample Preparation and Automatic Image Analysis, Polym. Eng. Sci. 19 (1979) 377-382.

[5] Carling M.J. and Williams J.G., Fiber length distribution effects on the fracture of short-fiber composites, Polym. Compos. 11 (1990) 307-313.

[6] Ulrych F., Sova M., Vokrouhlecky J. and Turcic B., Empirical relations of the mechanical properties of polyamide 6 reinforced with short glass fibers, Polym. Compos. 14 (1993) 229-237.

[7] Talbot H., Analyse morphologique de fibres minérales d'isolation, Thèse de Doctorat de l'École Nationale Supérieure des Mines de Paris (1993).

[8] Avérous L., Quantin J.C., Lafon D. and Crespy A., Granulometric characterization of short fiberglass in reinforced polypropylene. Relation to processing conditions and mechanical properties, Int. J. Polymer Analysis Characterization 1 (1996) 339-347.

[9] Fischer G. and Eyerer P., Measuring Spatial Orientation of Short Fiber Reinforced Thermoplastics by Image Analysis, Polym. Compos. 9 (1988) 297-304.

[10] Toll S. and Andersson P. O., Microstructural characterization of injection moulded composites using image analysis, Composites 22 (1991) 298-306.

[11] Clarke A.R., Davidson N. and Archenhold G., Measurements of fibre direction in reinforced polymer composites, J. Microsc. 171 (1993) 69-79.

[12] Avérous L., Quantin J.C., Lafon D. and Crespy A. Determination of 3D orientations in reinforced thermoplastics, using scanning electron microscopy, Acta Stereol. 14/1 (1995) 69-74.

[13] Avérous L., Quantin J.C., Lafon D. and Crespy A., Evolution of the three-dimensional orientation of glass fibers in injected isotactic polypropylene, Polym. Eng. Sci. (To be published).

[14] Waterbury M.C. and Drzal L.T., Determination of fiber volume fractions by optical numeric volumefraction analysis, J. Reinf. Plast. Comp. 8 (1989) 627-636.

[15] Ess J.W., Hornsby P.R., Lin S.Y. and Bevis M.J., Characterisation of dispersion in mineral filled thermoplastics compounds, Plast. Rub. Process. Applic. 4 (1984) 7-14.

[16] Coster M. and Chermant J.L., Précis d'analyse d'images (Les Presses du CNRS, 1989).

[17] Serra J., Image Analysis and Mathematical Morphology Vol. 1 (Academic Press, 1982).

[18] Stoyan D., Kendall W.S. and Mecke J., Stochastic Geometry and its Applications (J. Wiley and Sons Ltd, 1987).

[19] Sawyer L.C. and Grubb D.T., Polymer Microscopy (Chapman and Hall, 1987).

[20] Bailey R. and Rzepka B., Fibre orientation mechanisms for injection molding of long fibre composites, Int. Polym. Process. 1 (1991) 35-41.

[21] Underwood E.E., Quantitative Stereology (Addison-Wesley Publishing Company, London, 1970).

[22] Jeulin D., Analyse morphologique de la répartition spatiale, Note Interne $\mathrm{N}^{\circ} \mathrm{N}-28 / 88 / \mathrm{MM}$, École des Mines de Paris (1988).

[23] Saxl I., Pelikan K., Rataj J. and Besterci M., Quantification and modelling of heterogeneous systems (Cambrige International Science Publishing, 1995).

[24] Wendrock H. and Hübel R., Characterization of microstructural anisotropy of steels by means of mathematical morphology, Acta Stereol. 13/1 (1994) 143-148.

[25] Pelikan K., Saxl I. and Ponizil P., Germ-grain model of short-fibre composites, STERMAT 94, Pologne (1994) pp. 389-396. 